\title{
Radiation dose awareness of radiologic technologists in major Jordanian hospitals
}

\author{
M. Alhasan ${ }^{1 *}$, M. Abdelrahman ${ }^{1}$, H. Alewaidat ${ }^{1}$, Y. Khader ${ }^{2}$ \\ ${ }^{1}$ Department of Allied Medical Sciences, Faculty of Applied Medical Sciences, Jordan University of Science and \\ Technology (JUST), Irbid, Jordan \\ 2Department of Public Health-Community Medicine, Faculty of Medicine, Irbid, Jordan
}

\section{- Short report}

\author{
${ }^{*}$ Corresponding author: \\ Dr. Mustafa Alhasan, \\ Fax: +962 27095123 \\ E-mail: mkalhasan@just.edu.jo \\ Revised: Aug. 2015 \\ Accepted: Sept. 2015 \\ Int. J. Radiat. Res., April 2016; \\ 14(2): 133-138 \\ DOI: 10.18869 /acadpub.ijrr.14.2.133
}

\begin{abstract}
Background: Radiology staff needs to justify the radiation exposures in order to protect themselves and others from radiation risks. The aims of this study were to examine the awareness level of radiation dose and protection amongst radiographers and to compare their performance between major Jordanian hospitals. Materials and Methods: A cross-sectional survey was conducted in 4 major Jordanian hospitals. A total of 85 radiographers agreed to participate in the study. The questionnaire included demographic information, general radiation protection, radiation dose estimation and radiation induced cancer risk sections. Results: The average total score of radiographers in all hospitals was less than $50 \%$. The lowest score was for radiation induced cancer questions section (34\%). There was no significant difference in the level of awareness between radiographers from different hospitals except for the radiation dose awareness section $(p=0.001)$. Experience and training courses did not correlate significantly with the total score or with the score of individual sections. Conclusion: The level of radiation dose and protection awareness amongst radiographers in the sampled Jordanian hospitals is inadequate. At this stage, establishing an annual assessment of the radiographer's awareness through the Jordanian national radiation agency is highly encouraged.
\end{abstract}

Keywords: Professional development, dose, radiography, questionnaire.

\section{INTRODUCTION}

Radiology has a critical role in both, the diagnosis and therapy of diseases. Most patients who visit hospitals are requested to undertake a radiologic examination. Some of these examinations expose the body to ionizing radiation and has been reported to increase the risk of cancer (1-5), such as conventional X-ray, fluoroscopy, and computed tomography (CT).

CT scan is a major source of public radiation dose (6). The frequent use of CT has been reported to contribute for most of cancer cases in the United States (7). For example, the incidence of cancer risk from CT scan amongst young population is about 1 in 1,000 (8). However, the risk of cancer has only been well established at high levels of radiation doses, whereas the effects of routine diagnostic and low radiation doses are not fully understood (9).

Referring physicians and radiology staff should work together to reduce radiation risks associated with medical imaging. Medical personnel must justify the X-ray exposures (10) before performing a radiologic examination (11) and to know how to protect themselves and others from radiation risks. This requires adequate level of awareness of the harmful effects of radiation and how to reduce them. Determining the level of awareness is critical to identify any deficiencies in order to overcome them and eventually reduce radiation hazards to all who are involved in the process of radiologic examination. Unfortunately, several 
studies have assessed this level and most of them reported significant inadequacy $(10,12-19)$.

The aims of this study were to assess the awareness level of radiation dose and protection amongst radiographers and also to compare their performance in major Jordanian hospitals.

\section{MATERIALS AND METHODS}

This study was approved by the institutional review board at Jordan University of Science and Technology. A qualified radiographer conducted the survey in 4 major hospitals, including three governmental hospitals (GH1, GH2, GH3) and a public educational hospital (EH). Radiographers from all radiology departments, including routine X-ray imaging, angiography, CT, fluoroscopy, MRI, US and nuclear medicine were invited to participate in the study. After explaining the aims of the research and obtaining the consent forms, participants were asked to fill the questionnaire. The questionnaire (appendix) included a demographic information section, a general radiation protection section, a radiation dose section, and a radiation induced cancer risk section. The questions were adopted from previous published questionnaires $(6,12,17)$. The questionnaire was available in Arabic and English versions.

For statistical analysis one-way ANOVA of unmatched groups was used to test the numerical variables, and Chi-square was used to test the categorical variables. Two values were assigned for evaluating the questions; 1 for correct answer and 0 for incorrect answer. Awareness score was calculated as the percentage of correct answers. The total score of the 17 awareness questions was compared amongst hospitals. Then, the score of each section was compared separately. The difference was considered significant if $p$-value was less than or equal to 0.05 (two-tailed test). Pearson's correlation coefficient was calculated to test the correlation between the experience and the percentage of trained radiographers with the questionnaire score. The numerical data were expressed as mean and standard error (SE). Statistical analysis was performed using Prism 5 (GraphPad, La Jolla, CA, USA).

\section{RESULTS}

A total of 85 radiographers agreed to participate in our study (GH1: 18, GH2: 22, GH3: 23, EH: 22). Demographic information of the participants is summarized in table 1 . There was no statistically significant difference in gender and work experience between hospitals except for the percentage of trained radiographers $(p=0.04)$. The questionnaire score results are summarized in table 2 . The average total score of all radiographers in all hospitals was less than $50 \%$. The lowest score was for radiation induced cancer questions section (34\%). There was no significant difference in the level of awareness between radiographers from different hospitals except for the radiation dose awareness section $(p=$ 0.001). Table 3 summarizes the results of correlation test. Experience and training courses did not correlate significantly with the total score or with the score of individual sections.

\section{DISCUSSION}

Our study aimed to examine the awareness level of radiation dose and protection amongst radiographers and to compare their

Table 1. Summary of demographic information of participants.

\begin{tabular}{|l|l|c|c|c|c|c|}
\hline \multicolumn{2}{|c|}{ Hospital } & GH1 & GH2 & GH3 & EH & P-value \\
\hline \multirow{2}{*}{ Gender } & Male & 8 & 14 & 10 & 14 & \multirow{2}{*}{0.34} \\
\cline { 2 - 6 } & Female & 10 & 8 & 13 & 8 & \\
\hline Experience (years) & $6.9 \pm 1.3$ & $5.8 \pm 0.8$ & $8.5 \pm 1.6$ & $7.0 \pm 1.0$ & 0.47 \\
\hline Percentage of trained radiographers & $30 \%$ & $55 \%$ & $48 \%$ & $70 \%$ & 0.04 \\
\hline
\end{tabular}
mean \pm SE


Table 2. Summary of awareness scores (mean \pm SE).

\begin{tabular}{|l|c|c|c|c|c|}
\hline \multicolumn{1}{|c|}{ Hospital } & GH1 & GH2 & GH3 & EH & $P$-value \\
\hline General radiation protection section & $40 \pm 4 \%$ & $47 \pm 4 \%$ & $45 \pm 4 \%$ & $44 \pm 2 \%$ & 0.51 \\
\hline Radiation dose section & $53 \pm 5 \%$ & $40 \pm 2 \%$ & $51 \pm 3 \%$ & $40 \pm 4 \%$ & 0.001 \\
\hline Radiation induced cancer section & $47 \pm 5 \%$ & $40 \pm 4 \%$ & $45 \pm 3 \%$ & $34 \pm 4 \%$ & 0.14 \\
\hline Total score & $46 \pm 3 \%$ & $43 \pm 2 \%$ & $47 \pm 3 \%$ & $40 \pm 3 \%$ & 0.27 \\
\hline
\end{tabular}

Table 3. Summary of correlation test results between questionnaire scores, experience and percentage of trained radiographers.

\begin{tabular}{|l|c|c|c|c|}
\hline \multirow{2}{*}{ Dependent variable } & \multicolumn{2}{c|}{ Experience } & \multicolumn{2}{c|}{ Percentage of trained radiographers } \\
\cline { 2 - 5 } & $\mathbf{R}^{\mathbf{2}}$ & $\boldsymbol{P}$-value & $\mathbf{R}^{\mathbf{2}}$ & $\boldsymbol{P}$-value \\
\hline General section score & 0.06 & 0.76 & 0.41 & 0.36 \\
\hline Radiation dose section score & 0.40 & 0.37 & 0.68 & 0.17 \\
\hline Radiation induced cancer section score & 0.15 & 0.61 & 0.88 & 0.06 \\
\hline Total score & 0.32 & 0.44 & 0.68 & 0.18 \\
\hline
\end{tabular}

performance in major Jordanian hospitals. The study was conducted in 4 major Jordanian hospitals. Three hospitals were public and one was educational. The questions were designed to evaluate the general awareness of radiation dose and protection of radiographers and to identify their weakness in different aspects. The results showed that the total score in all hospitals was less than 50\%, while the lowest score was for radiation induced cancer questions section (34\%). The level of experience or training courses did not influence the scores as there were no significant correlations found.

The results indicated weak radiation dose and protection awareness amongst radiographers, which was similar to previous studies. A study was conducted in 5 hospitals in London to investigate the radiation protection awareness amongst radiologists and radiographers. They found that the majority of the responses were incorrect regarding the estimation of radiation dose in different examinations (10). Another survey amongst radiographers in Pakistan revealed a strong need for training programs to increase the awareness level (14). Most of the published papers about the radiation awareness level were conducted amongst medical personnel other than radiographers. For example, a study that was conducted on general and specialist physicians in Iranian hospitals found that most medical doctors did not have enough awareness about the amount of radiation received by patients undertaking radiologic investigations (19).

To the best of our knowledge, there was no study performed to evaluate the radiographer's radiation dose and protection awareness level in Jordan. Although major public hospitals were included, comparison with private hospitals, radiology clinics could have improved the study in terms of sample size and clinical setting types. However, this study can bring the attention to the inadequate level of radiation dose and protection awareness in the sampled hospitals.

\section{CONCLUSION}

The results suggest weak radiation dose and protection awareness amongst radiographers. Lack of continuing professional development in radiation protection amongst radiographers in Jordan may have affected the awareness level. Further work is needed to identify the factors that have led to the inadequate level of awareness amongst radiographers and to investigate its consequences. At this stage, establishing an annual assessment of the radiographers' awareness through the 
Jordanian national radiation agency is highly encouraged.

\section{ACKNOWLEDGEMENTS}

We would like to thank the hospitals for the participation and their cooperation during this study. Thanks to Hamza Almasri and Majd Alkhaleli for their help in distributing the questionnaires and collecting the data. This work was funded by Jordan University of Science and Technology (Grant number: 20120222).

\section{Conflict of interest: Declared none.}

\section{REFERENCES}

1. Brenner D and Hall E (2007) Computed Tomography - An Increasing Source of Radiation Exposure. N Engl J Med, 357: 2277-2284.

2. Hall E and Brenner D (2008) Cancer risks from diagnostic radiology. Br J Radiol, 81: 362-378.

3. Maeder M, Verdun F, Stauffer J, Ammanna P, Ricklia H (2005) Radiation exposure and radiation protection in interventional cardiology. Kardiovaskuläre Medizin, 8: 124132.

4. Yu S, Cheung Y, Chan T, Kung C, Yuen M (2001) Reduction of radiation dose to patients undergoing barium enema by dose audit. Br J Radiol, 74: 162-165.

5. Wong $C$, Huang B, Sin H, Wong W, Yiu K, Chu Yiu Ching T (2012) A questionnaire study assessing local physicians, radiologists and interns' knowledge and practice pertaining to radiation exposure related to radiological imaging. Eur J Radiol, 81: 264-268.

6. Soye J and Paterson A (2008) A survey of awareness of radiation dose among health professionals in Northern Ireland. Br J Radiol, 81:725-729.

7. Baumann B, Chen E, Mills A, Glaspey L, Thompson N, Jones M, Farner M (2011) Patient perceptions of computed tomographic imaging and their understanding of radiation risk and exposure. Ann Emerg Med, 58: 1-7.
8. Thomas K, Parnell J, Haidar S, Moineddin R, Charkot E, BenDavid G, Krajewski C (2006) Assessment of radiation dose awareness among pediatricians. Pediatr Radiol, 36: 823-832.

9. Brenner D, Doll R, Goodhead D, et al. (2003) Cancer risks attributable to low doses of ionizing radiation: Assessing what we really know. Proc Natl Acad Sci U S A, 100: 13761-13766.

10. Koutalonis M and Horrocks J (2012) Justification in clinical radiological practice: a survey among staff of five London hospitals. Radiat Prot Dosimetry, 149: 124-137.

11. Li X, Samei E, Segars W, Sturgeon G, Colsher J, Toncheva G, Yoshizumi T, Frush D (2011) Patient-specific radiation dose and cancer risk estimation in CT: Part II. Application to patients. Med Phys, 38: 408-419.

12. Eksioglu A and Uner C (2012) Pediatricians' awareness of diagnostic medical radiation effects and doses: are the latest efforts paying off? Diagn Interv Radiol, 18: 78-86.

13. Lee C, Haims A, Monico E, Brink J, Forman H (2004) Diagnostic CT Scans: Assessment of patient, physician, and radiologist awareness of radiation dose and possible risks. Radiology, 231:393-398.

14. Shah A, Begum N, Nasreen S, Khan A (2007) Assessment of radiation protection awareness levels in medical radiation science technologists - a pilot survey. JPMI, 21: 169-172.

15. Mojiri $M$ and Moghimbeigi A (2011) Awareness and attitude of radiographers towards radiation protection. JPS, 2: 2008-4978.

16. Carpeggiani C, Kraft G, Caramella D, Semelka R, Picano E (2012) Radioprotection (un)awareness in cardiologists, and how to improve it. Int J Cardiovasc Imaging, 28: 1369 $-1374$.

17. Luk S, Leung J, Cheng C (2010) Knowledge of radiation dose and awareness of risks: a cross-sectional survey of junior clinicians. J Hong Kong Col Radiol, 13: 189-194.

18. Osullivan J, Oconnor O, Oregan K, Clarke B, Burgoyne L, Ryan M, Maher M. (2010) An assessment of medical students' awareness of radiation exposures associated with diagnostic imaging investigations. Insights Imaging, 1: 86-92.

19. Sani K, Jafari $M$, Mohammadi $M$, Mojiri M, Rahimi A (2009) Iranian physicians' knowledge about radiation dose, received by patients in diagnostic radiology. Iran $J$ Radiat Res, 6: 207-212. 


\section{Appendix}

\section{Questionnaire sections:}

Demographic section

1. What is your gender?

A. Male

B. Female

2. How long is your experience?

3. Have you had courses/training related to radiology?

General radiation protection awareness section

1. What is the ratio between a radiation dose from chest $\mathrm{X}$-ray and a dose from annual background radiation?

A. 1:100

B. $1: 10$

C. $1: 1$

D. $10: 1$

2. What is the patient's absorbed dose from a chest X-ray?
A. $\quad 0.02 \mathrm{mSv}$
B. $0.2 \mathrm{mSv}$
C. $2 \mathrm{mSv}$
D. $20 \mathrm{mSv}$

3. How much radiation does the public receive from medical imaging?
A. $\quad 1.5 \%$
B. $5 \%$
C. $15 \%$
D. $\mathbf{5 0 \%}$

4. What is the annual dose limit for patients in $\mathrm{mSv}$ ?
A. 10
B. 20
C. 50
D. Unlimited

5. Estimate the radio-sensitivity of 5 year-old in comparison to an adult?
A. The same
B. Less
C. 5 times more
D. 10 times more

6. In pediatric population, gonads are the most sensitive organs. Which of the following organs comes next?
A. Liver
B. Kidney
C. Stomach
D. Urinary bladder

7. Which of the following has a prolonged period of time of emitting radiation?
A. PET-CT
B. Abdomen $\mathrm{CT}$
C. Abdomen MRI
D. Barium study 
8. In pediatric population, gonads are the most sensitive organs. Which of the following organs comes next?

A. Liver

B. Kidney

C. Stomach

D. Urinary bladder

9. Which of the following has a prolonged period of time of emitting radiation?

A. PET-CT

B. Abdomen $\mathrm{CT}$

C. Abdomen MRI

D. Barium study

\section{Radiation dose awareness section}

Estimate the equivalent radiation dose for each of the following examinations in terms of number of Chest X-rays? (Example: the dose of Chest $\mathrm{X}$-ray $=1$ chest $\mathrm{X}$-ray).

\begin{tabular}{|c|c|c|c|c|c|}
\hline \multirow{2}{*}{ Examination } & \multicolumn{5}{|c|}{ Equivalent radiation dose (number of chest X-rays) } \\
\cline { 2 - 6 } & $0-1$ & $1-10$ & $10-50$ & $50-100$ & $100-500$ \\
\hline 8. Abdominal X-ray & & & & & \\
\hline 9.Barium enema & & & & & \\
\hline 10.Abdominal US & & & & & \\
\hline 11.Brain MRI & & & & & \\
\hline 12.Abdominal CT & & & & & \\
\hline
\end{tabular}

\section{Radiation induced cancer awareness section}

What is the probability of inducing cancer for each of the following examinations?

\begin{tabular}{|c|c|c|c|c|c|}
\hline \multirow{2}{*}{ Examination } & \multicolumn{5}{|c|}{ Probability of inducing cancer } \\
\cline { 2 - 6 } & $\begin{array}{c}\text { Less than 1 in a } \\
\text { million }\end{array}$ & $\begin{array}{c}1 \text { in a } \\
\text { million }\end{array}$ & $\begin{array}{c}1 \text { in } \\
300000\end{array}$ & $\begin{array}{c}1 \text { in } \\
10000\end{array}$ & $\begin{array}{c}1 \text { in } \\
5000\end{array}$ \\
\hline 13.Abdominal X-ray & & & & & \\
\hline 14.Barium enema & & & & & \\
\hline 15.Abdominal US & & & & & \\
\hline 16.Brain MRI & & & & & \\
\hline 17.Abdominal CT & & & & & \\
\hline
\end{tabular}

